\title{
Views of Adolescent Bhutanese Refugees on Home Learning During School Shutdown Across the Period of COVID-19
}

\author{
Nabaraj Mudwari ${ }^{1}$, Kim Beasy, Carol Murphy, and Monica Cuskelly \\ University of Tasmania, Australia
}

\begin{abstract}
The coronavirus (COVID-19) pandemic is now a global crisis, resulting in the intermittent closure of many schools, worldwide. The school closures are believed to have affected adolescents' education, particularly for vulnerable adolescents including those from a refugee-background. The study explores the home learning experiences of adolescent Bhutanese refugees in Tasmania, Australia and draws on social capital theory to interpret findings. Interviews with adolescent Bhutanese refugees revealed four overarching themes: disengagement from learning, the experience of isolation, the complexity of family relationships and motivation through relationships. This article makes an important practical and theoretical contribution to home learning through challenging Putnam's binary distinction between bonding and bridging and suggesting alternative conceptualisations based on the role of bonding in the creation of bridging social capital. These findings have potential implications for the development of mitigation measures to support refugee-background students under extraordinary circumstances.
\end{abstract}

Keywords: adolescent refugees, COVID-19, education, home learning, social capital.

Home learning became obligatory in Australia and elsewhere in the world because of school closures introduced as a physical distancing response to COVID-19. The psychological, social and educational effects of home learning on young people continue to be apparent (Garbe et al., 2020; Lamb et al., 2020; Liu et al., 2020; Masters et al., 2020; Wang et al., 2020). During home learning periods, teachers need to work differently to support their students' learning and wellbeing. Reports and research published in Australia (Brown et al., 2020; Lamb et al., 2020; Masters et al., 2020) and elsewhere (Andrew et al., 2020a; Bol, 2020) suggest the impacts of COVID-19 on educational success and wellbeing are disproportionately experienced by disadvantaged students.

Although research about the impact of school closures during COVID-19 lockdowns on education is still limited, recent evidence supports claims that minority learners are detrimentally impacted by school shutdowns (Azevedo et al., 2020; Drane et al., 2021; Maldonado \& De Witte, 2020, United Nations Educational, Scientific and Cultural Organisation [UNESCO], 2020), further exacerbating inequalities in education and society more generally (Armitage \& Nellums, 2020). In a briefing paper submitted to the Australian Government Department of Education, Skills and Employment, Lamb et al. (2020) pointed out that extant research highlights difficulties faced by vulnerable children while learning from home, and that efforts to determine additional supports for those who are most likely to struggle with home learning are needed. Kollender and Nimer (2020), in their policy brief, argued that remote learning during COVID-19 was challenging and potentially opened gateways for institutional discrimination against adolescent refugees. Children and adolescent refugees

\footnotetext{
${ }^{1}$ Corresponding Author E-Mail: nabaraj.mudwari@utas.edu.au
} 
faced compounding challenges during school closures, including poor housing conditions, limited parental resources, and language and technology barriers that impacted their ability to engage with learning (Edmonds \& Flahault, 2021; Primdahl et al., 2021). The evidence highlights a need to further unpack the effects of school closures on migrant and refugeebackground young people to contribute to the development of mitigation efforts (Liu et al., 2020; Viner et al., 2020; Wang et al., 2020).

This paper reports on a study that examined home learning experiences of adolescent refugees during school shutdowns due to COVID-19 in Tasmania, Australia.

The research questions were:

1. What were the home learning experiences of adolescent Bhutanese refugees during school shutdown due to COVID-19?

2. How were social networks utilised by adolescent Bhutanese refugees to manage the challenges posed by the COVID-19 school shutdown?

\section{Educational Experiences of Adolescent Refugees}

Adolescent refugees potentially have complex vulnerabilities due to the emotional, psychological and economic traumas experienced during forced migration and subsequent integration processes (Marshall et al., 2016). Many of them have experienced limited and disrupted education and low-quality instruction before they arrive in their country of resettlement (Dryden-Peterson, 2015). After resettlement, one of the fundamental concerns for adolescent refugees is to successfully adjust to a new schooling environment (Kia-Keating \& Ellis, 2007). Australian studies have shown adolescent refugees experience negative stereotypes, economic hardship, language barriers, peer problems, and racial discrimination at schools (Australian Institute of Family Studies, 2016; Correa-Velez et al., 2017; Lau et al., 2018; Molla, 2019). Although most adolescent refugees have a lower level of education and language proficiency (in the language of the host country) than their peers, they have strong aspirations for the future (Hos, 2020; Shakya et al., 2010).

Educational institutions are considered critical sites for creating opportunities and are seen to play an integral role in supporting the integration of adolescent refugees (Block et al., 2014; Kia-Keating \& Ellis, 2007; Taylor \& Sidhu, 2012). However, adolescent refugees continue to face specific challenges and barriers to access or complete school in their host country (United Nations High Commissioner for Refugees [UNHCR], 2019). Successful schooling of adolescent refugees in host countries has been found to depend upon multiple, complex, and interrelated factors, including those related to social, cultural and linguistic opportunities and skills. A study of African adolescent refugees in Canada found their academic success in schools was impeded by a lack of academic support at home, limited language capability, the pace of the curriculum, fear and distrust of teachers, and a disinclination to speak out in class (Kanu, 2008). Two Australian studies conducted with African adolescent refugees found they experienced similar challenges (Harris \& Marlowe, 2011; Molla, 2019). In addition to these, Molla (2019) identified structural barriers such as racial discrimination in the educational setting that inhibited academic engagement.

Mastery of the host country's language is instrumental for communicating and accessing education and is also one of the determinants of an individual's position within broader social situations (Ager \& Strang, 2008). According to Bourdieu (1991), proficiency in the local language provides capacity to effectively participate in education and the broader civic space. Linguistic competence is recognised as a major hurdle in the educational success of refugees. A study of Afghanis, Burmese and Sudanese adolescent refugees in Canada found that limited English proficiency constrained their ability to ask questions or seek clarification from teachers 
and to communicate with others. These difficulties led to them falling behind in class and restricted their interactions within the school community (Shakya et al., 2010).

School plays a central role in establishing meaningful connections for adolescent refugees and in developing a sense of belonging to their host country (Correa-Velez et al., 2017; Kia-Keating \& Ellis, 2007; Taylor \& Sidhu, 2012). A feeling of belonging at school has been linked to higher levels of adolescents' physical and emotional wellbeing and academic performance and achievement (de Heer et al., 2016; Uptin et al., 2013). Cambodian firstgeneration youths in the United States built a sense of belonging to their school community that helped them fashion a rich and successful school experience through the accumulation of various social and cultural resources (Tang et al., 2013). Schools and teachers can help adolescents feel they belong by fostering a positive relationship with them, and good relationships between teachers and adolescents have been found to contribute positively to school belonging and engagement (Due \& Riggs, 2016; Isik-Ercan, 2015). However, COVID19 brought about a sudden change to teacher-student relationships. For example, a study with Scottish teachers found that the rapid shift from face-to-face classes to remote learning influenced their engagement with their adolescent students (McLennan et al., 2020). Teachers started using different methods of communication with adolescents and their families from those used before COVID-19 lockdown, which extended teachers' role beyond the school premises. While school closures reduce access to learning supports and resources (Mudwari et al., 2021), they also disrupt access to peers (Skovdal \& Campbell, 2015).

Social networks inside and outside school are vitally important to adolescent refugees (Isik-Ercan, 2012) as these connections generate resources through social relations. Social networks external to the school can generate conditions that facilitate adolescents' academic success (Major et al., 2013). As an example, Wilkinson et al. (2017) found that resources and support, provided by places of worship and youth and sporting groups, fostered the capacities of adolescent refugees to integrate within the local community and engage effectively with their education.

Challenges for culturally and linguistically diverse migrant and/or refugee (CALDM/R) adolescents extend to the Australian higher education context, as identified by Mupenzi et al. (2020) in their investigation of the impacts of COVID-19. They found that inaccessibility of vital infrastructure for online learning, unavailability of familiar and trusted support services, and inability to form and sustain academic and social networks inhibited the engagement of CALDM/R adolescents with learning. While immediate family and ethnic community are important social networks, connections to teachers, peers and friends are also significant for education and wellbeing. The role of cultural and social resources and how these can be drawn upon to build social capital to support adolescent refugees' educational achievement and wellbeing has not received much attention. There is reason to suppose social capital potentially facilitates greater educational achievements for students (Hommes et al., 2012; Pishghadam \& Zabihi, 2011). Social capital, and how it is leveraged by refugee-background and migrant adolescents, may be of particular importance at a time of substantial pressure, such as the recent crisis due to the global pandemic.

\section{Theoretical Framework}

Historically, scholars across disciplines have had an interest in the influences and uses of social capital (see Adelman \& Morris, 1967; Hirschman, 1958), but current scholarship on social capital is most frequently attributable to the contributions of Bourdieu (1986), Coleman (1988, 1990) and Putnam (2000). For Bourdieu (1986), social capital was an important variable that determined an individual or group's social mobility and explained the ongoing reproduction of class relations. Coleman (1990) defined social capital as "intangible social resources based 
on social relationships that one can draw upon to facilitate action and to achieve goals" (p. 302). Putnam (2000) argued that community prosperity could be achieved through the quality of the local social network. Taken together, these positions indicate that strong connections between individuals and groups are necessary if the mobilisation of resources within networks is to be used in the pursuit of desired outcomes. This understanding of social capital has been used to explain diverse outcomes, including community development (Agnitsch et al., 2006), status attainment (Lin, 1999), economic growth (Beugelsdijk \& Smulders, 2009), exploration of new opportunities (Isham, 1999), and educational achievement (Coleman, 1988; Israel \& Beaulieu, 2004), with these benefits applying especially to immigrants (Zhou \& Kim, 2006). In terms of refugee children and adolescents, out-of-school resources - mainly from home and co-ethnic community networks - may create informal and social opportunities for accruing social capital (Morrice, 2007; Pastoor, 2017; Wilkinson et al., 2017).

Much of the early evidence available on social capital was gathered to identify the amount and levels of social capital present within individuals, groups, or the community, and to examine outcomes (e.g., Portes \& Landolt, 1996). The focus of this early research was on the relative presence or absence of social networks to generate necessary social capital (see, Bourdieu, 1986; Coleman, 1988). Recently, social capital scholars have expanded the concept of social capital to allow for more nuanced interpretations. Putnam's (2000) interpretation, for example, relates social capital to the broader idea of social cohesion and differentiates the concept into two forms of social capital: bonding and bridging. Putnam's (2000) version of social capital allows for a more complex understanding of its various forms and functions and was selected for this study because of its relevance for understanding and explaining the value of social connectedness of adolescent refugees during the context of forced home learning.

According to Putnam (2000), bonding social capital accrues through strong ties within a family, group, or co-ethnic community. Thus, bonding social capital is the product of a sense of belonging that emerges from supportive relationships between people who have strong close relationships. For adolescent refugees, it is accrued through positive relationships with immediate family members, relatives, close friends and members of their cultural group (Correa-Velez et al., 2010; Joyce \& Liamputtong, 2017). On the other hand, bridging social capital refers to more distant social relationships built with heterogeneous groups such as workmates and members of other socio-cultural and ethnic communities (Pastoor, 2017). Bridging social capital provides access to valuable sources of knowledge and skills needed by adolescent refugees to escape their marginalised position and associated social exclusion in their new country of resettlement (Morrice, 2007). For adolescent refugees, these networks potentially form at educational institutions such as schools. Thus, educational institutions could be a key place for adolescent refugees to accumulate bridging social capital as they can build relationships with teachers and peers from the host nation. However, COVID-19 changed the face of education from face-to-face to distance teaching and learning, thus reducing the capacity of adolescent refugees to strengthen and extend bridging relationships at schools.

The bonding and bridging social capital that adolescents accrue has been found to influence their sense of belonging to a new place (Putnam, 2000), as well as experience of their own co-ethnic community (Bigelow, 2007). Nevertheless, Putnam's (2000) work is not without critique. For example, Strang and Quinn (2019) argued that Putnam's theory, which distinguished bonding and bridging as two separate elements, was a misconstrual of social capital and suggested the relationship between these two aspects of social capital was more akin to a continuum. In this paper, bonding and bridging forms of social capital are used as a theoretical lens to interpret adolescent refugees' home learning experiences during school shutdown due to COVID-19, and to consider whether and how these constructs intersected in this context. 
Policymakers and academics have discussed social capital as a possible resource for addressing diversity (Portes \& Vickstrom, 2011) while also enabling educational achievement (Palmer \& Gasman, 2008) and shaping educational aspirations (Byun et al., 2012). There has, however, been little attention paid to how social capital might be used to understand the impact of events that significantly disrupt access to a physical education site for refugee adolescents. Although some studies have been conducted during COVID-19 with the general student population in Australia (e.g., Evans et al., 2020) and elsewhere (e.g., Andrew et al., 2020a; Dong et al., 2020), there is sparse literature regarding the experience of adolescent refugees. While some research has suggested an important role for social networks in generating social capital for adolescent refugees concerning their education (Major et al., 2013; Wilkinson et al., 2017), as yet there is a paucity of literature about how this may occur when they are continuing their education from home. The pandemic provides a living lab that allows exploration of the role that schools and social networks may have in relation to the development and exchange of social capital for this minority group.

\section{Positioning the Researchers}

The researchers of this study are academics situated at a regional campus of a higher education institution in Tasmania, Australia. Collectively, the team's research interests include inclusive education, refugee education, and cultural studies. The first author is part of the Bhutanese community and speaks the same language as the participants who contributed to the research and comes from the same Southern part of Nepal.

\section{Method}

This paper reports on findings from a larger interpretive-qualitative study which explored experiences of integration of adolescent refugees in Australia. For this article, we include data about home learning while schools were closed due to COVID-19. An interpretative inquiry was selected to frame the study, in recognition that there is no objective truth or 'one' experience, but rather, that a multiplicity of realities exists. This framing values all experiences equally and works effectively as a mechanism to share the voices that are often silenced, or absent from dominant accounts (Jones et al., 2014; Liamputtong, 2007). In addition, interpretive research values the emic perspectives of the participants (Liamputtong, 2020) and, in this study, brings richness to exploring home learning experiences. Following Creswell's (2007) advice, the authors were reflexive in interpreting the complexities of the multiple realities involved in the study and in presenting the views on home learning during school shutdown across the period of COVID-19 in participants' own words as much as possible.

\section{Participants}

Participants were 16 adolescent Bhutanese refugees aged between 16 and 18 years from Tasmania, Australia, all of whom were attending secondary school. Participants had been in Australia from between 3 months and 7 years on humanitarian resettlement visas. They came to Australia with their families and spoke Nepali and English, the latter with various degrees of fluency. All the participants were born in a refugee camp in Nepal. Seven of the participants were interviewed after they resumed school following the COVID-19 school shutdown in June 2020. Data from these seven participants are reported in this article. Table 1 depicts the demographic details of these participants. Pseudonyms have been used throughout the paper. 
Table 1

Demographic Details of the Participants

\begin{tabular}{lllll}
\hline Participants & Gender & Age & Family structure & $\begin{array}{l}\text { Time in } \\
\text { Australia }\end{array}$ \\
\hline Parbeena & Female & 17 & Stepfamily with sibling & 3 months \\
Parush & Male & 17 & Two-parent family, only child & 6 months \\
Nishu & Female & 16 & Single mother family with sibling & 6 months \\
Dhommi & Male & 18 & Two-parent family with siblings & 3 years \\
Abhisekh & Male & 18 & Single mother family with sibling & 3 years \\
Pooja & Female & 18 & Two-parent family with siblings & 5 years \\
Karusa & Female & 18 & Extended family with sibling & 7 years \\
\hline
\end{tabular}

Note. The participants' identities were replaced by their chosen pseudonyms.

\section{Procedure}

Ethics approval was granted by University of Tasmania Social Science Human Research Ethics Committee (\#H0018366). The first author (who undertook the data collection) is from the same linguistic and cultural background as the participants.

Purposeful sampling techniques allow the researcher to select participants who have the potential to provide information regarding the research questions to be addressed (Palinkas et al., 2015) and so this approach was adopted for the wider study. Participants from refugee backgrounds were recruited through third party organisations which provide services to refugees in Tasmania, Australia. These organisations advertised the project using posters in their centres and providing information sheets. Interested participants contacted the first author directly. Information sheets and consent forms were prepared in Nepali and English and sent to potential participants who had indicated an interest in participating in the study.

The data were collected in two phases. In the first phase, individual semi-structured interviews were undertaken to explore participants' social networks and integration experiences. These were followed in the second phase by 'draw and tell' and 'photo-elicitation' methods, both with accompanying interviews. 'Draw and tell' involves participants being asked to draw a map or sketch of their social networks, and photo-elicitation involves discussion of participants' photos. For this study, participants were asked to take 10-15 new photographs or to choose from their collection, photos that made them happy, particularly those that captured places or people where/with whom they felt safe. These visual techniques assist individuals in expressing feelings and aid meaning-making (Ainsworth et al., 2011; Darbyshire et al., 2005; Wright, 2007). They were thought to be useful in this instance as they could support the effective participation of respondents who had difficulty or reluctance in expressing themselves with words. Participants were provided with a three-week timeframe to complete the drawing and photo-taking tasks and were invited to discuss their images in an individual interview.

All the interviews were conducted at a place of the participants' choosing, using the participant's preferred language. All the participants preferred Nepali for interviews. The initial interviews were audio-recorded and the discussions related to the 'draw and tell' and 'photoelicitation' activities were video-recorded. In addition, video-recording was used to capture hand movements to assist decipher the meaning of those conversations that included artefacts (Brown et al., 2008; Didkowsky et al., 2010). Audio- and video-recordings were transcribed prior to analysis.

Returning transcripts to research participants for 'member checks' is useful to establish the confirmability and credibility of the research (Lincoln \& Guba, 1985; Miles \& Huberman, 1994). In this study, transcripts were distributed to participants who were asked to confirm that their views were accurately represented. Five participants did so, and a further two indicated 
that they had read the transcripts but did not provide any comment. Those who responded confirmed that the transcripts were an accurate account of the conversation.

In Tasmania, all face-to-face classes were paused between mid-March and early June 2020 to limit COVID-19 spreading. Due to these restrictions, all data collection relevant to the seven participants whose data are included in this study was conducted after the participants resumed school.

\section{Data Analysis}

All the audio- and video-recorded semi-structured interviews, 'draw and tell' and 'photo-elicitation' discussions were transcribed and translated into English by the first author. Two were back-translated into the original language by an accredited bilingual expert to ensure the translations' robustness, validity, and reliability (Tyupa, 2011). This process confirmed that translation was accurate because no significant differences were observed in the translations.

All the transcripts were uploaded to NVivo (version 12). Transcripts were coded individually. Following Saldaña (2013), a holistic method of coding was used to identify basic themes and issues in the data, rather than to consider the data line-by-line. It was evident from the data that home learning during school closure was an important issue for the participants. A thematic analysis pertaining to participants' home learning experience was conducted following Braun et al.'s (2019) six analytic stages: reading and familiarisation, coding, generating and reviewing themes, producing a thematic map, naming and defining themes, and finalising the analysis through writing. This process was not linear but iterative, and stages were revisited as analysis progressed. The final thematic structure was discussed and agreed upon after multiple discussions among all authors. A thick description of participants' quotes was presented in each theme to confirm integrity and trustworthiness (Geertz, 1973). Findings were interpreted based on the data and understanding of the relevant literature to ensure the credibility of the study.

\section{Findings}

The initial thematic analysis exercise led to the development of descriptive categories such as relationships at home and connections to school which were used to represent the various aspects of participants' home learning experiences. A review of these initial categories resulted in four overarching themes: (1) disengagement from learning, (2) the experience of isolation, (3) the complexity of family relationships, and (4) motivation through relationships. These four themes were finalised through iterative discussions within the research team and are illustrated using direct quotations from the participants.

\section{Theme 1: Disengagement from Learning}

Whilst support, physical space, and facilities were mentioned as contributors to engagement with learning in schools, participants suggested that parental and teacher support was important to educational participation during home learning. Participants described educational support from their parents as important for their home learning; for example, "Parents' support is most important" (Dhommi). However, all the participants did not feel they received parental educational support because of their parents' low levels of educational achievement. Dhommi further stated, "I could not ask my parents for their assistance because they are not well educated, so I could not complete my assignments." In addition, parents' language proficiency and digital literacy were barriers to the provision of educational support. For example, Abhisekh explained, "My mother can hardly communicate in English and doesn't 
have much computer knowledge. So, when I got stuck in my study, I couldn't turn to her for academic assistance."

Support from teachers was also seen as crucial for comprehending schoolwork because of the participants' own difficulties with English. Before lockdown, participants received language and tutorial support from the school, which was abandoned during the home learning period. As a result, they were not able to complete homework and assignments stipulated by their teachers. Participants reported that their schoolwork piled up because of insufficient guidance from schools. For example, Karusa explained, "There were a few contacts with teachers through the online learning system, but you know, that was not sufficient."

Some participants had a negative experience during the home learning period because they did not have an appropriate learning environment. Participants frequently mentioned that they did not engage much in school-related learning during the COVID-19 lockdown. They attributed this to living in a small house where they could not establish a dedicated learning space. Due to the shared nature of living, they were often distracted from their learning. For example, "There is no private space for learning at home. I don't have a separate study room as we are living in a small house" (Dhommi). Like Dhommi, Karusa and Pooja struggled to establish a conducive learning environment with minimal distractions at home, which Karusa shared with her grandparents, aunts and sister. She could not find a quiet space due to the activities of others. She explained, "I couldn't concentrate on my study because my grandparents were busy with phone calls to relatives in the USA, asking after each other's wellbeing." Pooja struggled to cope with the school materials and synchronous online learning during the home learning period. Her difficulty was exacerbated by the noisy home environment. She stated, "It was tough for me to open the CANVAS [online learning platform] and find the tutorials, announcements and assignments. There were online classes on some subjects, but it was hard to understand due to the disturbances at home."

In addition to support and physical space, poor internet affected participants' online learning. For example, "I didn't get online lessons easily because it dropped out frequently. So, I couldn't understand the online lessons fully" (Parush). For some participants, unavailability of other resources such as reading materials impacted their capacity to engage with school tasks. Nishu stated, "It was hard to study from home due to lack of reading materials." Other participants had limited access to digital devices at home. A frequently cited reason for not having adequate digital devices included financial constraints. For example, Parbeena who had been in Australia for three months and was living in government-provided, temporary accommodation explained:

My parents are not working, so I don't have enough money to buy a good computer. I utilised a mobile which I brought from Nepal, but it's hard for online learning without a big screen, when I opened online classes on my mobile phone, which dropped out frequently (Parbeena).

\section{Theme 2: The Experience of Isolation}

Participants felt isolated during the lockdown due to a lack of social opportunities and an inability to participate in extracurricular activities. Participants reported they experienced loneliness due to isolation from their social networks. This isolation inhibited the opportunity to tap into valuable social connections that enabled participants to access information and progress. Participants reported that their social activities were paused because of school closure. They used to 'hang out' with their Bhutanese friends during their breaks at school. Participants could not join in their friends' birthday celebrations due to social gathering restrictions that hindered their socialisation opportunities. For example, "We didn't go out with friends 
[Bhutanese] because of restrictions and fear of infection. And there were no birthday celebrations anymore in the group which was boring" (Parbeena). Like Parbeena, Nishu also felt isolated at home during the school shutdown. She explained her feeling of isolation: "It was hard for me to learn from home where there were no face-to-face classes and no peers around you who you could ask things that you didn't know."

Social contact of the participants during religious activities was also disrupted due to lockdown. Due to the physical distancing measures, they could not attend their place of worship, which impacted their socialisation. For example, "We could not meet people at the Church and attend its activities" (Pooja). For some participants, community soccer was a place of socialisation, but lockdown impeded their interactions there: "We used to play soccer in the evenings with friends but couldn't anymore" (Karusa). Participants also indicated that community soccer was not only for socialisation but was also a place where they could seek important information related to work, education and other aspects of life in Australia. For example, "I got useful information about car driving from my friends and sometimes they also helped me to drive a car, but it wasn't happening during lockdown" (Abhisekh).

Other key socialisation activities were disrupted during home learning. Participants unanimously reported that their physical education and extracurricular activities were abandoned due to school closure. The school shutdown impeded formal opportunities to participate in physical education, as well as outdoor and social activities with their friends; thus, they felt isolated and bored at home. Sport activities created confidence among participants. For example, Parush came to Australia with his family six months before the interviews. He was unfamiliar with the Australian education system. Due to his low proficiency in English, he chose sports and outdoor education as his two subjects. He was happy with these subjects because he was able to demonstrate competence in them. Parush explained, "I chose sports and outdoor education subjects due to my low English." He further indicated that sports facilitated friendships with his peers, "I played soccer well, so other friends and teachers liked me." Participants also indicated that participation in sports and outdoor activities provided them with a sense of connection to their school and community. For example, Dhommi stated:

\section{School life was good as I can show my soccer skills to my teachers and friends. I am good at it because I have played soccer since my childhood. However, there was no more soccer in school and community due to the lockdown, and it was boring that you couldn't connect with people around you (Dhommi).}

\section{Theme 3: The Complexity of Family Relationships}

Family relationships were found to be an important aspect of learning new things during home learning. During the unprecedented school shutdown, participants experienced both positive and negative interactions with their families due to more time spent with them than usual. Quality family time was reported by some participants who said they spent more time with family members than before lockdown, creating a favourable environment for learning more about their family. For example, Parbeena, who had recently arrived in Australia, said, "The school shutdown was not all bad for me" and she described a positive experience with her family. She spent the lockdown doing various household tasks, such as cleaning and decorating and participated in games and activities with her sister. She further indicated that the lockdown had also extended her relationship with translocal family members, who were not living in the same house: "We frequently contacted family members in the USA, Canada and Nepal during that period." Participants who had recently arrived in Australia spent more time with their family members during the school shutdown than those who had been in Australia for some 
time, likely due to their limited social networks within their ethnic community and the host society. Like Parbeena, other recently arrived participants such as Parush and Nishu also reported positive experiences during the lockdown. Participants also had the opportunity to learn more about family history and culture from their parents and got the opportunity to learn the host society's language, culture and social system from virtual interactions with their families, friends and relatives who had been in Australia for an extended period of time. For example, "As a newcomer, I don't have many people to contact outside home. I had enough time to interact with my family and relatives in Australia and learned about many things from their lived experience" (Parush). Some participants reciprocated the opportunity to learn from their parents by assisting them with language learning, "I got a chance to teach my mother about simple English conversation things" (Nishu).

The home learning experience was not so favourable for other participants. Some experienced a conflictual situation with their parents due to increased time spent on digital devices at home. Participants who had been in Australia for a more extended period suggested some negative interactions with their family members because they (the participants) prioritised social networks outside the home. Lockdown disrupted their capacity to interact with those in their networks face-to-face and dramatically increased their engagement with social networking sites such as Facebook and video games to connect with their existing social networks. For instance, Abhisekh, who had been in Australia for more than three years, indicated, "My mother wanted me to study most of the time, but I could not; instead, I spent most of my time on PUBG [a video game] and Facebook with my friends." Other participants such as Dhommi, Karusa and Pooja also had been in Australia for more than three years and had similar experiences to Abhisekh. Dhommi stated, "My parents did not like me to be involved on digital devices for a long period of time with my friends, which I like most." Dhommi indicated that his parents wanted him to be doing something creative and not spending as much time with his friends on social networking sites; these were spoiling his creativity, in their view. Pooja indicated that "My parents didn't like me to wake up late as I usually went to sleep late as I sat up watching movies because there was no school." Karusa stated that her mother was not happy with her during the school shutdown period because her mother expected her to do household chores and look after her younger brother most of the time. This expectation created conflict between them. She explained:

It was very hard to spend all the time where there was all family present at home. Especially, my mother wanted me to do the cooking and cleaning and also look after my brother. So, you know, it was boring to be involved in this stuff all the time (Karusa).

\section{Theme 4: Motivation through Relationships}

Relationships with parents and teachers were valued by the participants. Participants felt motivated when their parents and teachers communicated with them. Some participants reported that their parents talked to them about educational matters, and this motivated them to work hard on their studies. For example, Pooja indicated that her parents were literate in their mother tongue, but they could not directly support her homework and assignments due to low English proficiency. Still, they frequently talked to her about education which motivated her to complete her schoolwork. Similar to Pooja, Parush's parents were unable to provide educational assistance to him. Although they were illiterate, they frequently asked Parush to focus on study and encouraged him to spend time on his online lessons and schoolwork. 
Both of my parents are illiterate, but they always told me that if I get good marks in my study, I can get good jobs, making my life easier in Australia. They said they didn't get the opportunity to go to school, so they don't have good jobs. My parents' lived experiences in education always inspired me to study (Parush).

Karusa's experience was very similar:

There was no academic support at home as my parents were literate in the Nepali language. But they spent much of their time with me as they lost their jobs. We had good conversations during that time. Most of the conversations were related to my education. They wanted me to be a nurse as they didn't get the chance to study much (Karusa).

Participants stated that their parents utilised familial networks to source information about future careers. For example, Nishu stated, "She [mother] wanted me to be a childcare worker as she got advice from my cousin who said it was a good job for girls." Similar to Nishu, Dhommi's parents also talked about future aspirations. Dhommi's parents asked their translocal family members about the possible job opportunities for him. Dhommi stated, "During the lockdown, my parents were involved in talking most of the time with the relatives in the USA and Canada and asked about the job opportunities after my school education."

The teacher-student relationship was another key motivator for engaging in schoolwork. Participants reported that they had some positive experiences with teachers. Adolescents were happy when they felt their teachers cared about them. The caring relationship with teachers was exemplified by sending emails to their students, calling on them in online discussions, and responding to their queries. Adolescents liked their teachers to communicate with them. It was more meaningful to those adolescents who were new to schools. For example, Parush was a recently arrived student who had limited social networks. So, contact from his teacher encouraged him to participate in his lessons.

I was new to the school as we recently came to Australia. I knew few people in the school. I was anxious about my home learning, but I was happy when the English teacher sent me an email when I missed a couple of her online lessons (Parush).

Participants also reported that they felt a sense of closeness to their teachers when they noticed them, and some teachers facilitated a sense of belonging to their classes.

It's huge for me that the teacher called me by my name in our online group lessons. It just makes me feel accepted that she notices me a lot. Yes, those types of things make me feel how close I am to her (Parbeena).

\section{Discussion}

The aim of this study was to explore home learning experiences from the perspectives of adolescent refugees during the pandemic. Partnerships between families, schools and communities are critical for children's overall learning and education (Emerson et al., 2012; Muller, 2009). However, mandatory home learning during COVID-19 shared the schools' 
teaching responsibilities with families (Lamb et al., 2020), which positively and negatively impacted the generation of bonding and bridging social capital.

\section{Increased Opportunities to Build Bonding Social Capital}

Our data indicate that the recently arrived participants spent more time with their families than before lockdown, creating a favourable environment for strengthening the family relationship. For example, Parbeena stated, "We frequently contacted family members in the USA, Canada and Nepal during that period." They had the opportunity to learn from their parents and siblings. They were involved in learning practical skills such as cooking and home decorating from their parents. Participants also reported that they got the opportunity to learn family history and culture from their parents and grandparents during the home learning period. They reciprocated the opportunity to learn from their parents and assisted them with language learning and household chores. Participants also reported that interaction with translocal families and relatives during lockdown strengthened their relationships and provided emotional and informational support. Enforced time at home allowed the deepening of relationships of the participants with immediate and translocal families, which created an opportunity to generate important bonding social capital such as trust, reciprocity and support (practical, emotional and informational) for their learning. This is an important finding as previous research has found that informal support from social networks is a key contributing factor to mitigate educational challenges (Andrew et al., 2020b; Strang \& Quinn, 2019). This finding strengthens evidence about the need to recognise the value of supportive social networks for the accumulation of bonding social capital for adolescents' educational engagement.

\section{Threats to Bonding Social Capital Due to Stressors}

While participants perceived that home learning created opportunities to develop bonding capital with family, they felt barriers in accruing it. Although the findings of this study showed that recently arrived participants spent quality family time during the home learning period and accrued necessary bonding social capital for learning and wellbeing, participants who had been in Australia for a more extended period had more negative interactions with their family members because they prioritised social networks outside the home. For example, Dhommi stated, "My parents did not like me to be involved on digital devices for a long period of time with my friends, which I like most." Participants also reported inadequate support and resources such as educational support from their parents, dedicated study spaces, computers and reliable internet during the home learning period. Participants reported increased engagement with social networking sites due to the disruption of their capacity to interact with those in their networks face-to-face. They reported conflictual relationships with their parents as their parents desired them to engage in schoolwork most of the time and interact with the family rather than with friends. These experiences underscore the complexities of matching parents' and adolescents' priorities when adolescents are in a mandatory home learning situation. This finding emphasised the participants' desire to spend time with their friends and showed the importance of social networks outside the home.

\section{Reduced Opportunity to Develop Bridging Social Capital}

Home learning due to COVID-19 reduced opportunities to extend social relationships. Social networking and participation in extracurricular activities are important for adolescent refugees, as they create opportunities to acquire knowledge, skills and social support necessary to cope with life challenges (Morrice, 2007). However, COVID-19 school closures forced these 
adolescents to learn remotely and made substantial changes to their daily routines, impeding the opportunity to participate in activities outside the home.

In this study, we found that these adolescent refugees recognised the importance of bridging connections; however, they experienced challenges connecting to their school, religious community, and the people with whom they played sport, due to the lockdown. They reported their extracurricular activities were abandoned, which impacted their opportunity for physical and social activities with their school friends and teachers. Some of these experiences prevented them from extending their bridging social capital. Previous research in Australia (e.g., Jeanes et al., 2015) and elsewhere (e.g., Doidge et al., 2020; Stura, 2019) found that participation in sports and extracurricular activities facilitates relatively straightforward access to bridging networks and connections and acts as an entry point for broader participation.

\section{Bonding and Bridging Social Capital: Interconnections}

Findings indicated that bonding capital was strengthened with family and the opportunities to develop bridging social capital with those outside the home were reduced. Opportunities to develop bridging capital were disrupted due to the disconnection from previous social networking opportunities (e.g., church, soccer). Putnams (2000) suggested a binary interpretation that tended to restrict understandings of bridging capital to tangible connections and 'bridges' (Pastoor, 2017). However, the participants in this study alluded to the motivation they received through their parents as a form of 'bridge' to undertaking their study, revealing that bonding and bridging capital were often interrelated.

Despite having inadequate resources and support for their home learning, some participants felt motivated during their home learning period. They indicated that their parents could not provide direct educational support due to their poor academic skills; nevertheless, they were inspired by their parents' lived experiences which encouraged them to focus on their studies. This appears to demonstrate that motivation to study resulted from a warm relationship with parents. Some recently arrived participants utilised the home learning period to accumulate necessary knowledge and information about schooling, available services and facilities, and opportunities and challenges in their newfound society by contacting their translocal family members who had been in their country of resettlement for an extended period. They also utilised the school lockdown period as an opportunity to spend time with family. This suggests that the bonding relationship with immediate and translocal family members can create avenues for generating bridging social capital. Participants gained bridging capital from their parents through their raised aspirations.

This study provides insights into how adolescents refugees seek educational support and the implications for generating bonding and bridging social capital. Findings suggested that bridging social capital often does not operate in isolation; in many cases, bonding relationships provided the foundation for participants to access bridging social capital, thereby supporting the critique of Putnam's binary distinction between bonding and bridging social capital (Cederberg, 2012; Morosanu, 2018; Strang \& Quinn, 2019; Wessendorf \& Phillimore, 2019). Putnam (2000) suggested that bonding social capital helps with 'getting by' and bridging social capital is more important for 'getting ahead'. As this study suggested, bonding and bridging social capital do not work in a straightforward manner, and a more nuanced interpretation of bonding and bridging social capital acknowledges the connections between these, rather than regarding them as separate categories. Data illustrated that the opportunities of building bridging social capital were impeded by the lockdown; however, participants utilised their bonding social networks (immediate and translocal family) to create avenues for accumulating bridging social capital. For example, participants were motivated by interactions with their parents to work hard on their studies. Some of the parents utilised familial networks to source 
information about a future career. This suggests that bridging social capital does not only accrue through tangible ways but may also be generated through more intangible ways such as through effective relationships with parents and relatives.

Our findings support previous Australian and international literature that has highlighted how bonding and bridging relationships with social networks are vital for adolescent refugees. Our study adds to the limited body of research that addresses the home learning experiences of adolescent refugees during the pandemic. Importantly, this study challenges Putnam's (2000) assertion that bridging social capital can only be accrued through inter-ethnic social networks. It supports the critique made by Strang and Quinn (2019), who suggested that bonding and bridging relationships was more akin to a continuum rather than being binary, and offers some increased depth to the conceptualisation of bridging/bonding based on interconnection between these aspects for the generation of social capital.

This paper reports some of the findings of a larger interpretive-qualitative study that explored adolescent refugees' broad integration experiences. The best research is always well planned; however, new circumstances arose to which we responded. This brings limitations with it. So, this paper was limited to home learning data during COVID-19 lockdown and did not include all participants' experience; therefore, the nature of this study is more opportunistic than designed. Although opportunistic research can never replace well-designed research, it can be necessary when unexpected but potentially influential circumstances arise. However, caution is required in relying on these findings and further investigation that examines these issues in other circumstances where students from a refugee-background are unable to attend school is necessary. Furthermore, this paper was based on interpretive-qualitative research and our findings cannot be generalised to other adolescent refugees because they are heavily contextualised and subjective. Nevertheless, it provides some insights into how adolescent refugees accrued bonding and bridging social capital and coped with the education challenges incurred by COVID-19 during home learning. Extending this research in other contexts would build our understanding of how adolescent refugees accrue social capital when they cannot participate in their usual 'social' places.

\section{Conclusion and Implications}

This study explored how adolescent refugees experienced home learning during school shutdowns introduced during COVID-19 lockdown periods in Australia. Although the closure of schools seemed critical to help contain COVID-19, adolescent refugees faced many educational challenges because of the shift to learning from home, an experience shared by many students across the globe. This study drew on social capital theory to reveal that parents, family members, friends and school personnel were important social networks for adolescent refugees in the generation of bonding and bridging social capital during home learning mandates. COVID-19 impacted participants' social capital, particularly their bridging social networks. It was revealed that family relationships were able to provide participants with bonding and bridging social capital in ways not previously identified.

Findings suggest that the generation of bonding and bridging social capital is not linear but comprises a complex, interconnected processes. Bonding relationships can provide practical and emotional support while creating opportunities to build and navigate bridging social capital. These findings suggest that refugee families and adolescents are resilient and resourceful in coping with the challenges of sudden school closures by utilising the bonding and bridging social capital available to them. This study provides insights for immigration and settlement services across the world about the interconnections between educational experiences of young people and family relationships, highlighting the importance of supporting new arrivals and established migrant families in maintaining and strengthening family relationships. 
The theoretical insights that emerged from this study have important implications for policy and practice regarding adolescent refugees' education wherever they are situated. The current pandemic situation provides the impetus for greater support for adolescent refugees. Enabling bonding and bridging social relationships to provide more social, linguistic and educational support, and strengthening families of adolescent refugees, are two key priorities that emerged from this study. Importantly, this study highlights the significance of bonding capital in enabling and generating bridging capital. There might be a role for schools and support services more broadly to support bonding and bridging relationships if any event that prevented schools from operating happened again.

Without targeted linguistic and educational supports during home learning periods, educationally disengaged adolescent refugees become more vulnerable, which can negatively affect individuals, schools and communities. Such adolescents may withdraw further from their learning and avoid engaging with peers and teachers, resulting in high attrition and poor academic achievement. This has implications for poor integration into the host society with later economic impacts. In supporting existing bonding and bridging relationships, school policies can play a role by providing meaningful opportunities for adolescent refugees to establish relationships with various social networks.

Targeted support for adolescent refugees must be embedded within the existing system, and it needs to be flexible enough to continue even under extraordinary circumstances. Although this study has derived some new insights into how bonding and bridging social capital accrued in relation to home learning during the pandemic, it is crucial that schools recognise they play an active role in generating the social capital that adolescent refugees need to 'get ahead'.

\section{References}

Adelman, I., \& Morris, C. T. (1967). Society, politics, and economic development: A quantitative approach. Johns Hopkins University Press.

Ager, A., \& Strang, A. (2008). Understanding integration: A conceptual framework. Journal of Refugee Studies, 21(2), 166-191. https://doi.org/10.1093/jrs/fen016

Agnitsch, K., Flora, J., \& Ryan, V. (2006). Bonding and bridging social capital: The interactive effects on community action. Community Development, 37(1), 36-51. https://doi.org/10.1080/15575330609490153

Ainsworth, S., Prain, V., \& Tytler, R. (2011). Drawing to learn science. Science, 333(6046), 1096-1097. https://doi.org/10.1126/science.1204153

Andrew, A., Cattan, S., Costa-Dias, M., Farquharson, C., Kraftman, L., Krutikova, S., Phimister, A., \& Sevilla, A. (2020a). Inequalities in children's experiences of home learning during the COVID-19 lockdown in England. Fiscal Studies, 41(3), 653-683. https://doi.org/10.1111/1475-5890.12240

Andrew, A., Cattan, S., Costa-Dias, M., Farquharson, C., Kraftman, L., Krutikova, S., Phimister, A., \& Sevilla, A. (2020b). Learning during the lockdown: Real-time data on children's experiences during home learning. https://ifs.org.uk/publications/14848

Armitage, R., \& Nellums, L. B. (2020). Considering inequalities in the school closure response to COVID-19. The Lancet Global Health, 8(5), e644. https://doi.org/10.1016/S2214109X(20)30116-9

Australian Institute of Family Studies (2016). Building a new life in Australia: The longitudinal study of humanitarian migrants. Findings from the first three waves. Australian Institute of Family Studies. https://www.dss.gov.au/sites/default/files/documents/03_2018/d17_1138305_bnla_rep ort_final_word_accessible_version.pdf 
Azevedo, J. P., Hasan, A., Goldemberg, D., Iqbal, S. A., \& Geven, K. M. (2020). Simulating the potential impacts of COVID-19 school closures on schooling and learning outcomes: A set of global estimates. (Policy Research Working Paper No. 9284). World Bank. https://doi.org/10.1596/1813-9450-9446

Beugelsdijk, S., \& Smulders, S. (2009). Bonding and bridging social capital and economic growth. Tilburg University.

Bigelow, M. H. (2007). Social and cultural capital at school: The case of a Somali teenage girl. Literacy Institute at Virginia Commonwealth University, 7-22. https://scholarworks.umass.edu/cgi/viewcontent.cgi?article=1007\&context=av_workss ite_acquisition\#page $=8$

Block, K., Cross, S., Riggs, E., \& Gibbs, L. (2014). Supporting schools to create an inclusive environment for refugee students. International Journal of Inclusive Education, 18(12), 1337-1355. https://doi.org/10.1080/13603116.2014.899636

Bol, T. (2020). Inequality in home schooling during the Corona crisis in the Netherlands. First results from the LISS Panel. https://doi.org/10.31235/osf.io/hf32q

Bourdieu, P. (1986). The forms of capital. In J. Richardson (Ed.), Handbook of theory and research for the sociology of education (pp. 241-285). Greenwood Press.

Bourdieu, P. (1991). Language and symbolic power. Harvard University Press.

Braun, V., Clarke, V., Hayfield, N., \& Terry, G. (2019). Thematic analysis. In P. Liamputtong (Ed.), Handbook of research methods in health social sciences (pp. 843-860). Springer.

Brown, K. M., Dilley, R., \& Marshall, K. (2008). Using a head-mounted video camera to understand social worlds and experiences. Sociological Research Online, 13(6), 31-40. https://doi.org/10.5153/sro.1818

Brown, N., Te Riele, K., Shelley, B., \& Woodroffe, J. (2020). Learning at home during COVID19: Effects on vulnerable young Australians. http://www.wscf.org.au/wpcontent/uploads/2020/06/Learning-at-home-during-COVID-19-Effects-on-vulnerableyoung-Australians.pdf

Byun, S. Y., Meece, J. L., Irvin, M. J., \& Hutchins, B. C. (2012). The role of social capital in educational aspirations of rural youth. Rural Sociology, 77(3), 355-379. https://doi.org/10.1111/j.1549-0831.2012.00086.x

Cederberg, M. (2012). Migrant networks and beyond: Exploring the value of the notion of social capital for making sense of ethnic inequalities. Acta Sociologica, 55(1), 59-72. https://doi.org/10.1177/0001699311427746

Coleman, J. S. (1988). Social capital and the creation of human capital. American Journal of Sociology, 94, (Supplement S 95-S120), 95-119. https://doi.org/10.1086/228943

Coleman, J. S. (1990). Foundations of social theory. Harvard University Press.

Correa-Velez, I., Gifford, S. M., \& Barnett, A. G. (2010). Longing to belong: Social inclusion and wellbeing among youth with refugee backgrounds in the first three years in Melbourne, Australia. Social Science and Medicine, 71(8), 1399-1408. https://doi.org/10.1016/j.socscimed.2010.07.018

Correa-Velez, I., Gifford, S. M., McMichael, C., \& Sampson, R. (2017). Predictors of secondary school completion among refugee youth 8 to 9 years after resettlement in Melbourne, Australia. Journal of International Migration and Integration, 18(3), 791805. https://doi.org/10.1007/s12134-016-0503-z

Creswell, J. W. (2007). Qualitative inquiry and research design: Choosing among five approaches. SAGE Publication.

Darbyshire, P., MacDougall, C., \& Schiller, W. (2005). Multiple methods in qualitative research with children: More insight or just more? Qualitative Research, 5(4), 417-436. https://doi.org/10.1177/1468794105056921 
De Heer, N., Due, C., Riggs, D. W., \& Augoustinos, M. (2016). "It will be hard because I will have to learn lots of English": Experiences of education for children newly arrived in Australia. International Journal of Qualitative Studies in Education, 29(3), 297-319. https://doi.org/10.1080/09518398.2015.1023232

Didkowsky, N., Ungar, M., \& Liebenberg, L. (2010). Using visual methods to capture embedded processes of resilience for youth across cultures and contexts. Journal of the Canadian Academy of Child and Adolescent Psychiatry, 19(1), 12-18.

Doidge, M., Keech, M., \& Sandri, E. (2020). Active integration: Sport clubs taking an active role in the integration of refugees. International Journal of Sport Policy and Politics, 12(2), 305-319. https://doi.org/10.1080/19406940.2020.1717580

Dong, C., Cao, S., \& Li, H. (2020). Young children's online learning during COVID-19 pandemic: Chinese parents' beliefs and attitudes. Children and Youth Services Review, 118, 105440. https://doi.org/10.1016/j.childyouth.2020.105440

Drane, C. F., Vernon, L., \& O'Shea, S. (2021). Vulnerable learners in the age of COVID-19: A scoping review. The Australian Educational Researcher, 48, 585-604. https://doi.org/10.1007/s13384-020-00409-5

Dryden-Peterson, S. (2015). The educational experiences of refugee children in countries of first asylum. Migration Policy Institute. https://www.lowan.nl/wpcontent/uploads/2020/02/FCD_Dryen-Peterson-FINALWEB.pdf

Due, C., \& Riggs, D. W. (2016). Care for children with migrant or refugee backgrounds in the school context. Children Australia, 42(3), 190-200. https://doi.org/10.1017/cha.2016.24

Edmonds, J., \& Flahault, A. (2021). Refugees in Canada during the first wave of the COVID19 pandemic. International Journal of Environmental Research and Public Health, 18(3), 947. https://doi.org/10.3390/ijerph18030947

Emerson, L., Fear, J., Fox, S., \& Sanders, E. (2012). Parental engagement in learning and schooling: Lessons from research. http://www.familyengagementcircle.org.au/application/files/3414/9845/6720/parentalengagement-in-learning-and-schooling_4.pdf

Evans, S., Mikocka-Walus, A., Klas, A., Olive, L., Sciberras, E., Karantzas, G., \& Westrupp, E. M. (2020). From "it has stopped our lives" to "spending more time together has strengthened bonds": The varied experiences of Australian families during COVID-19. Frontiers in Psychology, 11, 2906. https://doi.org/10.3389/fpsyg.2020.588667

Garbe, A., Ogurlu, U., Logan, N., \& Cook, P. (2020). COVID-19 and Remote Learning: Experiences of Parents with Children during the Pandemic. American Journal of Qualitative Research, 4(3), 45-65. https://doi.org/10.29333/ajqr/8471

Geertz, C. (1973). Deep play: Notes on the Balinese cockfight. In the interpretation of cultures. Basic Books.

Harris, V., \& Marlowe, J. (2011). Hard yards and high hopes: The educational challenges of African refugee university students in Australia. International Journal of Teaching and Learning in Higher Education, 23(2), 186-196.

Hirschman, A. (1958). The strategy of economic development. Yale University Press.

Hommes, J., Rienties, B., DE Grave, W., Bos, G., Schuwirth, L., \& Scherpbier, A. (2012). Visualising the invisible: A network approach to reveal the informal social side of student learning. Advances in Health Sciences Education, 17(5), 743-757. https://doi.org/10.1007/s10459-012-9349-0

Hos, R. (2020). The lives, aspirations, and needs of refugee and immigrant students with interrupted formal education (SIFE) in a secondary newcomer program. Urban Education, 55(7), 1021-1044. https://doi.org/10.1177/0042085916666932

Isham, J. (1999). The effect of social capital on technology adoption: Evidence from rural Tanzania. Department of Economics. 
Isik-Ercan, Z. (2012). In pursuit of a new perspective in the education of children of the refugees: Advocacy for the family. Educational Sciences: Theory and Practice, 12(4), 3025-3038. https://files.eric.ed.gov/fulltext/EJ1002997.pdf

Isik-Ercan, Z. (2015). Being Muslim and American: Turkish-American children negotiating their religious identities in school settings. Race, Ethnicity and Education, 18(2), 225250. https://doi.org/10.1080/13613324.2014.911162

Israel, G. D., \& Beaulieu, L. J. (2004). Laying the foundation for employment: The role of social capital in educational achievement. Review of Regional Studies, 34(3), 260-287. https://doi.org/10.52324/001c.8392

Jeanes, R., O'Connor, J., \& Alfrey, L. (2015). Sport and the resettlement of young people from refugee backgrounds in Australia. Journal of Sport and Social Issues, 39(6), 480-500. https://doi.org/10.1177/0193723514558929

Jones, S. R., Torres, V., \& Arminio, J. (2014). Negotiating the complexities of qualitative research: Fundamental elements and issues. Routledge.

Joyce, L., \& Liamputtong, P. (2017). Acculturation stress and social support for young refugees in regional areas. Children and Youth Services Review, 77, 18-26. https://doi.org/10.1016/j.childyouth.2017.03.016

Kanu, Y. (2008). Educational needs and barriers for African refugee students in Manitoba. Canadian Journal of Education, 31(4), 915-940.

Kia-Keating, M., \& Ellis, B. H. (2007). Belonging and connection to school in resettlement: Young refugees, school belonging, and psychosocial adjustment. Clinical Child Psychology and Psychiatry, 12(1), 29-43. https://doi.org/10.1177/1359104507071052

Kollender, E., \& Nimer, M. (2020). Long-term exclusionary effects of COVID-19 for refugee children in the German and Turkish education systems: A comparative perspective. https://ipc.sabanciuniv.edu/Content/Images/CKeditorImages/20200708-02075629.pdf

Lamb, S., Maire, Q., Doecke, E., Macklin, S., Noble, K., \& Pilcher, S. (2020). Impact of learning from home on educational outcomes for disadvantaged children. Centre for International Research on Education Systems and the Mitchell Institute, Victoria University. https://vuir.vu.edu.au/40386/1/Submission\%20to\%20Government_Impact\%20of\%20 Learning\%20from\%20Home.pdf

Lau, W., Silove, D., Edwards, B., Forbes, D., Bryant, R., Mcfarlane, A., Hadzi-Pavlovic, D., Steel, Z., Nickerson, A., Van Hooff, M., \& Felmingham, K. (2018). Adjustment of refugee children and adolescents in Australia: Outcomes from wave three of the Building a New Life in Australia study. BMC Medicine, 16(1), 1-17. https://doi.org/10.1186/s12916-018-1124-5

Liamputtong, P. (2007). Researching the vulnerable: A guide to sensitive research methods. SAGE Publication.

Liamputtong, P. (2020). Qualitative research methods (5th ed.). Oxford University Press.

Lin, N. (1999). Social networks and status attainment. Annual Review of Sociology, 25, 467487. https://doi.org/10.1146/annurev.soc.25.1.467

Lincoln, Y. S., \& Guba, E. G. (1985). Naturalistic inquiry. SAGE Publication.

Liu, J. J., Bao, Y., Huang, X., Shi, J., \& Lu, L. (2020). Mental health considerations for children quarantined because of COVID-19. The Lancet Child \& Adolescent Health, 4(5), 347349. https://doi.org/10.1016/S2352-4642(20)30096-1

Major, J., Wilkinson, J., Langat, K., \& Santoro, N. (2013). Sudanese young people of refugee background in rural and regional Australia: Social capital and education success. Australian and International Journal of Rural Education, 23(3), 95-105. https://search.informit.org/doi/pdf/10.3316/informit.845809019872687 
Maldonado, J. E., \& De Witte, K. (2020). The effect of school closures on standardised student test outcomes. British Educational Research Journal (Discussion Paper DPS20, 17). https://doi.org/10.1002/berj.3754

Marshall, E. A., Butler, K., Roche, T., Cumming, J., \& Taknint, J. T. (2016). Refugee youth: A review of mental health counselling issues and practices. Canadian $\begin{array}{lll}\text { Psychology/Psychologie } & \text { Canadienne, } & \text { 57(4), }\end{array}$ https://doi.org/10.1037/cap0000068

Masters, G. N., Taylor-Guy, P., Fraillon, J., \& Chase, A. M. (2020). Ministerial briefing paper on evidence of the likely impact on educational outcomes of vulnerable children learning at home during COVID-19. https://research.acer.edu.au/cgi/viewcontent.cgi?article=1025\&context=learning_proc esses

McLennan, C., Mercieca, D., \& Mercieca, D. (2020). What can I do? Teachers, students and families in relationship during COVID-19 lockdown in Scotland. Malta Review of Educational Research, 14(2), 163-181.

Miles, M.B., \& Huberman, A.M. (1994). Qualitative data analysis (2nd ed.). Sage Publication.

Molla, T. (2019). Educational aspirations and experiences of refugee-background African youth in Australia: A case study. International Journal of Inclusive Education, 25(8), 877895. https://doi.org/10.1080/13603116.2019.1588924

Morosanu, L. (2018). Researching migrants' diverse social relationships: From ethnic to cosmopolitan sociability? The Sociological Review, 66(1), 155-173. https://doi.org/10.1177/0038026117703905

Morrice, L. (2007). Lifelong learning and the social integration of refugees in the UK: The significance of social capital. International Journal of Lifelong Education, 26(2), 155172. https://doi.org/10.1080/02601370701219467

Mudwari, N., Cuskelly, M., Murphy, C., Beasy, K., \& Aryal, N. (2021). Impact of COVID-19 on refugee-background students during school shut down in Australia: A call for action. Teachers and Curriculum 21(1), 71-76. https://doi.org/10.15663/tandc.v21i1.356

Muller, D. J. A. (2009). Parental engagement: Social and economic effects. Australian Parents Council. https://www.austparents.edu.au/

Mupenzi, A., Mude, W., \& Baker, S. (2020). Reflections on COVID-19 and impacts on equitable participation: The case of culturally and linguistically diverse migrant and/or refugee (CALDM/R) students in Australian higher education. Higher Education Research and Development, 39(7), 1337-1341. https://doi.org/10.1080/07294360.2020.1824991

Palinkas, L. A., Horwitz, S. M., Green, C. A., Wisdom, J. P., Duan, N., \& Hoagwood, K. (2015). Purposeful sampling for qualitative data collection and analysis in mixed method implementation research. Administration and Policy in Mental Health and Mental Health Services Research, 42(5), 533-544. https://doi.org/10.1007/s10488-013-0528-y

Palmer, R., \& Gasman, M. (2008). "It takes a village to raise a child": The role of social capital in promoting academic success for African American men at a Black college. Journal of College Student Development, 49(1), 52-70. https://doi.org/10.1353/csd.2008.0002

Pastoor, L. D. W. (2017). Reconceptualising refugee education: Exploring the diverse learning contexts of unaccompanied young refugees upon resettlement. Intercultural Education, 28(2), 143-164. https://doi.org/10.1080/14675986.2017.1295572

Pishghadam, R., \& Zabihi, R. (2011). Parental education and social and cultural capital in academic achievement. International Journal of English Linguistics, 1(2), 50-57. https://doi.org/10.5539/ijel.v1n2p50

Portes, A., \& Landolt, P. (1996). The downside of social capital. The American Prospect, 26, 18-21. https://vtechworks.lib.vt.edu/handle/10919/67453 
Portes, A., \& Vickstrom, E. (2011). Diversity, social capital, and cohesion. The Annual Review of Sociology, 37, 461-479. https://doi.org/10.1146/annurev-soc-081309-150022

Primdahl, N. L., Borsch, A. S., Verelst, A., Jervelund, S. S., Derluyn, I., \& Skovdal, M. (2021). "It's difficult to help when I am not sitting next to them": How COVID-19 school closures interrupted teachers' care for newly arrived migrant and refugee learners in Denmark. Vulnerable Children and Youth Studies, 16(1), 75-85. https://doi.org/10.1080/17450128.2020.1829228

Putnam, R. D. (2000). Bowling alone: The collapse and revival of American community. Simon and Schuster.

Saldaña, J. (2013). The coding manual for qualitative researchers ( $2^{\text {nd }}$ ed.). SAGE Publication.

Shakya, Y. B., Guruge, S., Hynie, M., Akbari, A., Malik, M., Htoo, S., Khogali, A., Mona, S. A., Murtaza, R., \& Alley, S. (2010). Aspirations for higher education among newcomer refugee youth in Toronto: Expectations, challenges, and strategies. Refuge: Canada's Journal on Refugees, 27(2), 65-78. https://doi.org/10.25071/1920-7336.34723

Skovdal, M., \& Campbell, C. (2015). Beyond education: What role can schools play in the support and protection of children in extreme settings? International Journal of Educational Development, 41, 175-183. https://doi.org/10.1016/j.ijedudev.2015.02.005

Strang, A. B., \& Quinn, N. (2019). Integration or isolation? Refugees' social connections and wellbeing. Journal of Refugee Studies, 34(1), 328-353. https://doi.org/10.1093/jrs/fez040

Stura, C. (2019). "What makes us strong" - the role of sports clubs in facilitating integration of refugees. European Journal for Sport and Society, 16(2), 128-145. https://doi.org/10.1080/16138171.2019.1625584

Tang, J., Kim, S., \& Haviland, D. (2013). Role of family, culture, and peers in the success of first-generation Cambodian American college students. Journal of Southeast Asian American Education and Advancement, 8(1), 2. https://doi.org/10.7771/21538999.1057

Taylor, S., \& Sidhu, R. K. (2012). Supporting refugee students in schools: What constitutes inclusive education? International Journal of Inclusive Education 16(1), 39-56. https://doi.org/10.1080/13603110903560085

Tyupa, S. (2011). A theoretical framework for back-translation as a quality assessment tool. New Voices in Translation Studies, 7(1), 35-46.

United Nations Educational, Scientific and Cultural Organisation. (2020). Adverse consequences of school closures. https://en.unesco.org/covid19/educationresponse/consequences

United Nations High Commissioner for Refugees (2019). Stepping up: Refugee education in crisis. https://www.unhcr.org/steppingup/wpcontent/uploads/sites/76/2019/09/Education-Report-2019-Final-web-9.pdf

Uptin, J., Wright, J., \& Harwood, V. (2013). "It felt like I was a black dot on white paper": Examining young former refugees' experience of entering Australian high schools. The Australian Educational Researcher, 40(1), 125-137. https://doi.org/10.1007/s13384012-0082-8

Viner, R. M., Russell, S. J., Croker, H., Packer, J., Ward, J., Stansfield, C., Mytton, O., Bonell, C., \& Booy, R. (2020). School closure and management practices during coronavirus outbreaks including COVID-19: A rapid systematic review. The Lancet. Child \& Adolescent Health, 4(5), 397-404. https://doi.org/10.1016/S2352-4642(20)30095-X

Wang, G., Zhang, Y., Zhao, J., Zhang, J., \& Jiang, F. (2020). Mitigate the effects of home confinement on children during the COVID-19 outbreak. The Lancet, 395(10228), 945947. https://doi.org/10.1016/S0140-6736(20)30547-X 
Wessendorf, S., \& Phillimore, J. (2019). New migrants' social integration, embedding and emplacement in superdiverse contexts. Sociology, 53(1), 123-138. https://doi.org/10.1177/0038038518771843

Wilkinson, J., Santoro, N., \& Major, J. (2017). Sudanese refugee youth and educational success: The role of church and youth group in supporting cultural and academic adjustment and schooling achievement. International Journal of Intercultural Relations, 60, 210-219. https://doi.org/10.1016/j.ijintrel.2017.04.003

Wright, S. (2007). Graphic-narrative play: Young children's authoring through drawing and telling. International Journal of Education and the Arts, 8(8), 1-28.

Zhou, M., \& Kim, S. (2006). Community forces, social capital, and educational achievement: The case of supplementary education in the Chinese and Korean immigrant communities. Harvard Educational Review, 76(1), 1-29.

https://doi.org/10.17763/haer.76.1.u08t548554882477

\section{Notes on Contributors}

Nabaraj Mudwari is a PhD Candidate (Inclusive Education) in the School of Education at the University of Tasmania, Australia. His research interests include inclusive education, refugee integration, gender, social capital, translocality, intersectionality, and cultural studies.

Dr. Kim Beasy is a Lecturer (Curriculum and Pedagogy, Equity and Diversity) in the School of Education at the University of Tasmania, Australia. Her research interests include equity in educational access and attainment, sustainability education and teacher training.

Dr. Carol Murphy is a Senior Lecturer (Mathematics Education) in the School of Education at the University of Tasmania, Australia. Her research interests are in inclusive pedagogies, transformative professional development and the role of language in learning mathematics.

Dr. Monica Cuskelly is a Professor of Education at the University of Tasmania. Her research interests include the development of individuals with an intellectual or cognitive disability, their inclusion in all aspects of social life, and family functioning. 